\title{
Maternal Resveratrol Treatment Reduces the Risk of Mammary Carcinogenesis in Female Offspring Prenatally Exposure to 2,3,7,8-Tetrachlorodibenzo-p-Dioxin
}

\author{
Tássia C. de Lima e Silva ${ }^{1,2} \cdot$ Livia T. R. da Silveira ${ }^{3} \cdot$ Mariana F. Fragoso $^{2}$ • \\ Flávia R. M. da Silva ${ }^{2}$ - Meire F. Martinez ${ }^{3}$ - Joyce R. Zapaterini ${ }^{2}$ - Odair H. G. Diniz ${ }^{3}$. \\ Wellerson R. Scarano ${ }^{3}$ - Luis F. Barbisan ${ }^{3}$
}

Received: 24 May 2017 / Accepted: 31 July 2017 / Published online: 7 August 2017

(C) Springer Science+Business Media, LLC 2017

\begin{abstract}
Tetrachlorodibenzo-p-dioxin (TCDD) presents adverse effects on breast development/carcinogenesis. This study aimed to identify the ability of resveratrol (Res) to modify the adverse effects of TCDD in a female offspring. Pregnant female Wistar rats were allocated into four groups: TCDD, TCDD + Res, Res, and control. TCDD $(1 \mu \mathrm{g} / \mathrm{kg})$ was orally administered as a single dose on gestational day (GD) 15 , and Res was orally administered during GD10-21 and lactation at a dose of $20 \mathrm{mg} / \mathrm{kg} /$ day. Female offsprings were euthanized on a specific postnatal day (PND) for hormonal analysis (PND 22, 48-51), vaginal opening (PND 30-48), and mammary gland morphology (PND 22). Other females received two doses of N-nitroso-N-methylurea (MNU, $50 \mathrm{mg} / \mathrm{kg}$ ) on PNDs 22 and 51 and were euthanized on PND 24 (Ki-67, ER- $\alpha$ and apoptosis indexes or molecular analysis) or PND 180 (tumor assay). TCDD exposure altered the development of the mammary structure while these alterations were partially improved by maternal Res. Two days
\end{abstract}

Electronic supplementary material The online version of this article (doi:10.1007/s12672-017-0304-7) contains supplementary material, which is available to authorized users.

Luis F. Barbisan

barbisan@ibb.unesp.br

1 Departamento de Enfermagem, Centro Acadêmico de Vitória, UFPE- Universidade Federal do Pernambuco (UFPE), Vitoria de Santo Antão, PE 55608-680, Brazil

2 Departamento de Patologia, Faculdade de Medicina de Botucatu, Universidade Estadual Paulista (UNESP), Botucatu, SP 18610-307, Brazil

3 Departamento de Morfologia, Instituto de Biociências de Botucatu, Universidade Estadual Paulista (UNESP), Botucatu, SP 18618-689, Brazil after first MNU administration, some genes associated with apoptosis were altered in the mammary tissue from the TCDD group (Bax and Caspase 3 down- and Bcl-2 upregulated) but were also partially reestablished by maternal Res. Mammary gland bcl-2 and bcl-xl proteins expression was increased while the apoptosis index was reduced by TCDD exposure but restored by maternal Res. An increase in number of mammary tumors was observed in female offspring from the TCDD group compared to the other groups. The results indicate that most mammary changes induced in female offspring through TCDD exposure or after MNU administrations were reduced by maternal resveratrol treatment.

\section{Introduction}

Breast cancer is an estrogen-dependent, invasive, and potentially fatal malignancy. Its incidence in post-menopausal women has gradually increased in most Western and industrialized societies over the past few decades [1,2]. Besides genetic/familial factors, the risk of breast cancer in women is associated with reproductive parameters (i.e., older, later first full-term pregnancy, no full-term pregnancies) and lifestyle, as well as exogenous hormones (oral contraceptives, hormone replacement therapy) and late menopause [1,2]. Also, prenatal exposure to environmental chemicals may contribute to breast cancer developing in adulthood [3, 4]. Chemically induced models for mammary carcinogenesis in rodents have been suitable to study of risk factors, prevention, and tumor biology and development $[5,6]$. The most widely used rat chemically induced mammary carcinogenesis models are based on 7-12-dimethylbenz(a)anthracene (DMBA) or $\mathrm{N}$ nitroso- $N$-methylurea (NMU) exposure in susceptible and 
virgin female rat strains, whose tumors closely mimic human breast cancer $[5,6]$.

Various epidemiological and laboratory evidence has suggested that exposure to some environmental chemicals could play a role in the etiology of breast cancer through estrogen-related pathways or endocrine disruption effects $[4,7]$. Dioxins are a class of polyhalogenated compounds which include polychlorinated dibenzodioxins (PCDD), polychlorinated dibenzofurans (PCDF), and polychlorinated biphenyls (PCB) [8, 9]. 2,3,7,8-Tetrachlorodibenzo-p-dioxin (TCDD), an aryl hydrocarbon receptor (AhR) agonist, has been identified as the most potent dioxin and classified as a potential human carcinogen $[10,11]$. TCDD occurs as a byproduct in manufacturing and disposal processes, such as organochloride production, paper bleaching, and during high-temperature incineration of substances containing chloride. For populations living near dioxin-contaminated sites, additional exposure may occur by eating locally produced food, inhalation of particles, dermal contact with the soils, or other exposure pathways [12].

Some reports from the rodent studies indicate that TCDD, through AhR activation, impairs mammary epithelial cell proliferation and differentiation when administered in critical windows of mammary development [13-15]. TCDD exposure during mild gestation has revealed reproductive anomalies in rat offspring, including inconclusive reports of altered mammary development in dams and female offspring [13, 16-18]. A single dose of $1 \mu \mathrm{g} / \mathrm{kg}$ TCDD on gestation day (GD) 15 induced alterations in terminal end buds and ducts (TEB/TD), alveolar bud $(\mathrm{AB})$, and lobule (LOB) development in the mammary gland of the female offspring rats $[14,15]$ and increased the number of mammary tumors induced by a single dose of DMBA in the female offspring rats $[16,19]$. In contrast, direct correlations between human dioxin exposure and the development of breast cancer have not been consistent, with positive and negative associations [20-22].

Resveratrol (Res or 3,5,4',-trihydroxy-trans-stilbene)a naturally occurring polyphenol found in several human dietary sources, including grapes, berries, peanuts, and red wine - provides a number of health benefits including cardiovascular protection and cancer prevention [23-26]. Resveratrol, an AhR antagonist, is well tolerated and has low toxicity for humans while commercial dietary supplements contain doses ranging between 50 and $2000 \mathrm{mg}$ [27]. Various preclinical animal studies have investigated the cancer preventive potential of this natural compound, including rodent mammary tumor models [23, 28].

In chemically induced mammary tumors in female rats, dietary Res supplementation $(0.001 \%)$, before and after a single dose of DMBA, was shown to increase tumor latency and decrease mammary tumor incidences and multiplicity in female rats [29]. In a similar animal study, dietary Res supplementation $(0.1 \%)$, starting at birth and before and after DMBA administration, decreased the number of tumors per rat and increased mammary tumor latency and development [30]. In female rats initiated with a single DMBA administration, dietary RES supplementation $(0.001 \%)$, before and after carcinogen exposure, decreased the incidence of palpable mammary tumors [31]. Using NMU to induce mammary tumors and with Res given by gavage (10 or $100 \mathrm{mg} / \mathrm{kg} \mathrm{b.wt.),} \mathrm{Bhat}$ et al. (2001) showed that the higher dose of Res resulted in a significant delay in tumor formation and a reduction in tumor multiplicity [32]. On the other hand, Sato et al. (2003) showed that female rats treated daily with SC injections of Res (10 or $100 \mathrm{mg} / \mathrm{kg}$ b.wt.) on postnatal days 15-19 presented an increase in both the multiplicity of mammary tumors and the incidence of rats bearing tumors with $\geq 1 \mathrm{~cm}$ induced by NMU [33]. These animal studies suggest that caution must be applied in Res usage to prevent human breast cancer.

Since maternal exposure to a single dose of TCDD during pregnancy causes severe defects in mammary gland development and function [13-15], the objectives of this present study were to determine whether: (1) maternal Res intake during gestation and lactation could alter the potential noxious effects of prenatal TCDD exposure on mammary gland development and (2) maternal Res during gestation and lactation reduces the risk of mammary cancer induced by MNU in female offspring in adulthood. As such, this study is of clinical relevance since TCDD has an estimated half-life of 7.6 years in humans and dioxins have been detected in pregnant and lactating mothers (blood, cord blood, placenta, and breast milk) [34] with the potential to cause a host of diseases, including alterations to normal mammary gland growth and the development of mammary cancer [7].

\section{Materials and Methods}

\section{Chemicals}

2,3,7,8-Tetrachlorodibenzo-p-dioxin (TCDD, 99\% purity), resveratrol or 3,4',5-trihydroxy-trans-stilbene (Res, 99\% purity), and N-nitroso-N-methylurea (MNU, CAS Number 684-93-5) were purchased from Sigma-Aldrich, St. Louis, MO, USA.

\section{Animals, Breeding Protocol, and Treatments}

Animal protocols used in this study were consistent with the Ethical Principles for Animal Research adopted by the Brazilian College of Animal Experimentation (COBEA) 
and approved by the School of Medicine/UNESP Ethical Committee for Animal Research (CEUA, protocol number 1049/13).

Four-week-old virgin female $(n=60)$ and male $(n=30)$ Wistar rats were obtained from the Multidisciplinary Center for Biological Research (CEMIB, UNICAMP, Campinas-SP, Brazil). The animals were placed into polypropylene cages containing laboratory-grade pine shavings, which was used as bedding and maintained in a room under a controlled temperature $\left(22 \pm 2{ }^{\circ} \mathrm{C}\right)$, relative humidity $(55 \pm 10 \%)$, lighting conditions (12 h light/12 h dark photoperiod), and continuous ventilated air. Adult female Wistar rats (12 weeks old) in proestrus were mated 2:1 with proven-fertile male rats in the cage for $12 \mathrm{~h}$ (dark period). Sperm present in the vaginal smear and the identification of the estrus phase of the estrous cycle was considered gestational day 0 (GD0). These procedures were performed until the required number of pregnant females to each experimental group was reached. Upon confirmation of pregnancy, female rats (10 dams/group) were kept in individual cages and were randomly distributed into four groups (Fig. 1): TCDD, dams received a single dose of $1 \mu \mathrm{g}$ TCDD/kg body weight (b.wt.) by gavage on gestational day (GD) 15 [16] and a daily gavage of Res vehicle (ethanol 8\%) during GDs 10-21 and lactation; TCDD/Res, dams received a single dose of TCDD $(1 \mu \mathrm{g} / \mathrm{kg}$ b.wt.) by gavage on GD15 and daily gavage of Res (20 mg/kg b.wt.) [35] during GDs 10-21 and lactation; Res, dams received a single dose of TCDD vehicle (corn oil) by gavage on GD 15 and a daily gavage of Res ( $20 \mathrm{mg} / \mathrm{kg}$ b.wt.) during GDs 10-21 and lactation; and control, dams received a single dose of TCDD vehicle (corn oil) by gavage on GD 15 and a daily gavage of Res vehicle (ethanol 8\%) during GDs 1021 and lactation. Due to their low solubility in water, TCDD and Res were diluted in corn oil and hydroalcoholic solution (water/ethanol 92:8v/v), respectively. Also, since TCDD can be transferred to offspring [16] via a lactational route, Res was administered during the lactational period. Food and water were provided ad libitum to the dams.

After parturition, male and female offsprings were identified by measuring the anogenital distance and genital papilla and/or nipple identification. The litter size was adjusted to eight pups/litter and the gender ratio was 4:4 (female/male) as possible. Litters were kept with the dams until the weaning period, and weighed on postnatal days $0,7,14,22$, and 51. Female offsprings were euthanized to determinate serum hormonal levels (PND 22 and 48-51) and mammary gland morphology analysis (PND 22) (Fig. 1). Other females received two intraperitoneal (i.p.) doses of MNU (50 mg $/ \mathrm{kg}$ b.wt.) [36] on PNDs 22 and 51, and they were euthanized on PND 24 (48 h after first MNU administration, for Ki-67, estrogen receptor alpha $($ ER- $\alpha)$, apoptosis and molecular analysis) or PND 180 (23 weeks after second MNU administration for tumor assay). All animals were euthanized under sodium pentobarbital anesthesia (single i.p. dose of $30 \mathrm{mg} / \mathrm{kg}$ b.wt.) (Fig. 1).

\section{Hormone Analysis and Vaginal Opening}

Immediately before euthanasia on PNDs 22 and 48-51 (estrous phase), blood samples were collected by cardiac puncture to further determine serum estradiol and progesterone levels ( 1 pup/little, $n=10$ each group). Serum estrogen and progesterone levels were determined using an automatic ultrasensitive Vitros ECI chemiluminescent analyzer (Johnson \& Johnson Orthoclinical Diagnostics, Division, Rochester, NY, USA) with sensitivities of $0.1-3814 \mathrm{pg} / \mathrm{mL}$ for estradiol and $0.15-60 \mathrm{ng} / \mathrm{mL}$ for progesterone, as described in a previous study [37]. The vaginal opening time (VO, assessed daily starting on PND 30) was recorded as an indicator of puberty. All female offspring rats from all groups (1 pup/little, $n=10$ each group) were evaluated daily, and the day of complete $\mathrm{VO}$ was suitably recorded.

\section{Mammary Gland Whole Mount Staining and Analyses}

On PND 22, the right abdominal mammary glands from female offsprings ( 1 pup/little, $n=06$ each group) were removed. Next, the mammary glands were air dried for 10 to 15 min on a clean glass slide, and fixed in buffered formalin $10 \%$ for $48 \mathrm{~h}$. The slides were washed in $70 \%$ ethanol, rinsed in water, and stained with Carmine $(1 \mathrm{~g})$ and aluminum potassium sulfate dodecahydrate ( $2.5 \mathrm{~g}$ ) (Sigma-Aldrich Co., EUA) for 2 days. Then, mammary whole mounts were dehydrated in sequential steps of ethanol (70, 95, and 100\%), cleared in xylene and mounted using Permount and coverslipped [38]. The mammary gland tree was photographed using a magnifying glass at $\times 1$ magnification (Leica MZ12-Japan-DF C 420) connected to a capture system and image analysis. Three different parameters were measured for each mammary gland tree which represented its outgrowth: ductal elongation, transverse growth, and lateral growth. The mean number of terminal end buds (TEB) and terminal ducts (TD) in the external margin of the mammary gland was determined [38] under a Bx 53F microscope (Olympus, Japan, $\times 20$ objective).

\section{Mammary Tissue, Gene Expression, and Immunohistochemistry Analyses}

On PND 24 (48 $\mathrm{h}$ after first MNU administration), the right and left abdominal mammary glands from the female offspring group were removed. Total RNA was extracted from frozen right abdominal mammary tissue samples (1 pup/little, $n=05$ each group) using the Rneasy Mini kit (Qiagen, Hilden, Germany) followed by on-column DNA digestion. RNA samples were solubilized in nuclease-free water (Qiagen, Hilden, Germany), and their concentration and integrity were evaluated on a NanoVue ${ }^{\mathrm{TM}}$ Plus (GE Healthcare) and an Agilent 2100 bioanalyzer (Agilent Technologies, Boeblingen, Germany), respectively. Equal quantities $(60 \mathrm{ng} / \mu \mathrm{L})$ of total RNA from 
Fig. 1 Experimental design (for details see the Materials and Methods section)

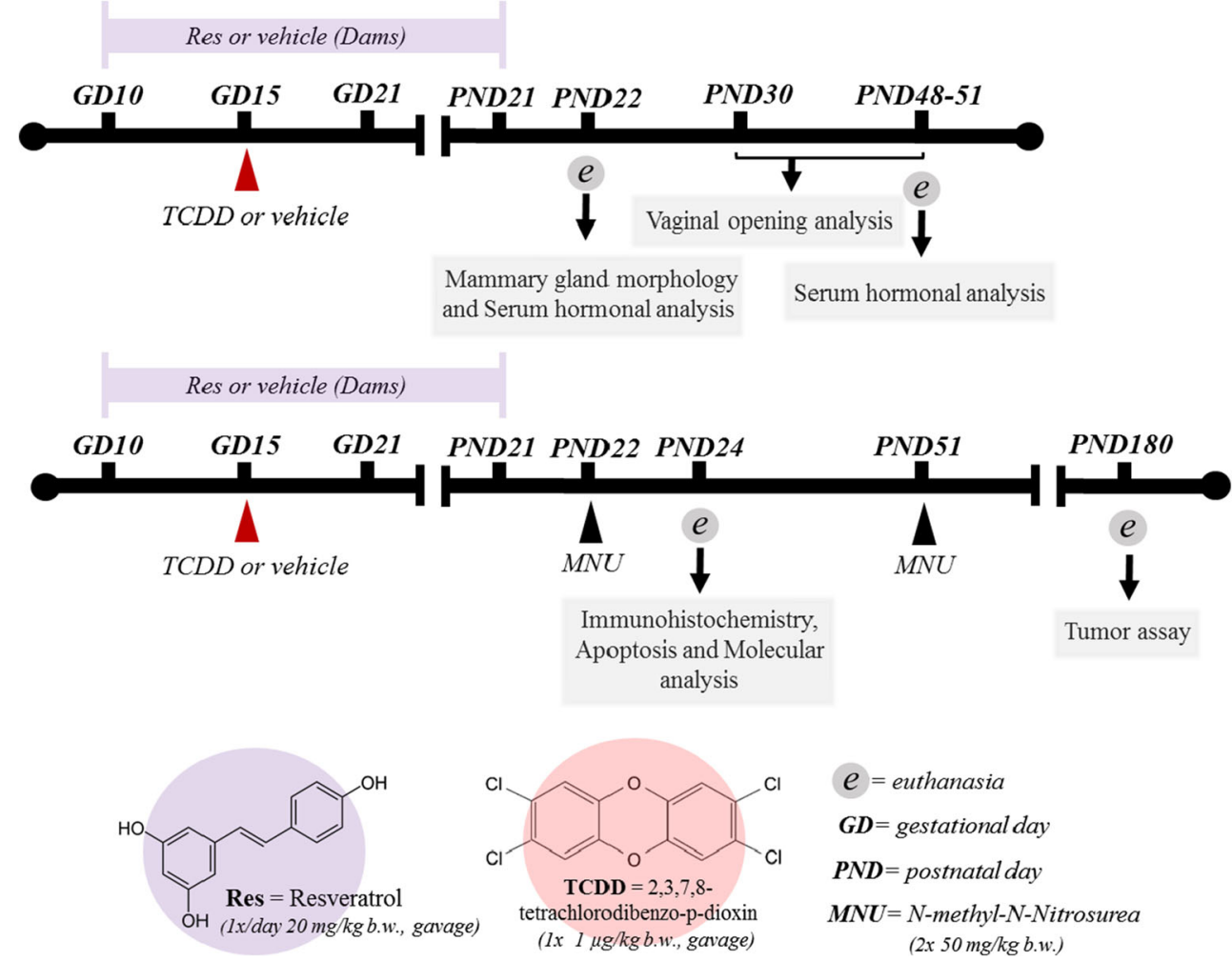

each sample were reverse-transcribed to first-strand cDNA using SuperScriptIV First Strand SuperMix (Invitrogen ${ }^{\mathrm{TM}}$, Life Tech, USA) according to the manufacturer's instruction.

RNA expression profiles were compiled using a 96-well TaqMan ${ }^{\circledR}$ Array Cards (TAC)-based real-time polymerase chain reaction (PCR). The custom TAC assessed 91 genes involved in oxidative metabolism, pro- and antioxidant activity, cell proliferation, DNA damage, DNA repair, and apoptosis (Supplementary Data 1). $\beta$-Actin, Gapdh, Gusb, and Hprt1 were used as housekeeping genes to normalize mRNA expression. Target genes were amplified using the TaqMan ${ }^{\circledR}$ Universal Mastermix II (Life Technologies, USA) by a cycling protocol of heat activation at $50^{\circ} \mathrm{C}$ for $1 \mathrm{~min}$ and denaturation at $95^{\circ} \mathrm{C}$ for $10 \mathrm{~min}$ followed by 40 cycles of $95^{\circ} \mathrm{C}$ for $15 \mathrm{~s}$ and $60{ }^{\circ} \mathrm{C}$ for $1 \mathrm{~min}$. Fluorescence detection was performed on QuantStudio ${ }^{\text {TM }} 12$ K Flex Real-Time PCR System (Life Technologies, USA).

Left abdominal mammary tissue ( 1 pup/little, $n=05$ each group) was fixed in $10 \%$ phosphate-buffered formalin for $24 \mathrm{~h}$, embedded in paraffin blocks, cut into 5 - $\mu \mathrm{m}$-thick sections, and stained with hematoxylin/eosin (HE) or immunohistochemically for Ki-67 or ER- $\alpha$. Histological sections were placed on silanized-coated slides, deparaffinized, and rehydrated with graded alcohol. Sections were subjected to Pascal pressure chamber retrieval in a citrate acid buffer at $\mathrm{pH} 6.0$ at $120{ }^{\circ} \mathrm{C}$ for $3 \mathrm{~min}$. Endogenous peroxidase was blocked with $3 \% \mathrm{H} 2 \mathrm{O} 2$ in phosphate-buffered saline (PBS) for $10 \mathrm{~min}$ in the dark. After washing with PBS, slides were incubated with nonfat milk in PBS for $60 \mathrm{~min}$. Sections were then incubated with rabbit monoclonal anti-Ki-67, 1:200 dilution (Abcam, UK) and mouse monoclonal anti-ER-a/6F11, 1:50 dilution (BioCare Medical, Concord, CA, USA) primary antibodies. This step was followed by biotinylated universal link and streptavidin HPR (20 min each) solutions (LSAB System-HRP, DakoCytomation, Denmark). Chromogen color development was accomplished using 3,3-diaminobenzidine tetrahydrochroride (Sigma-Aldrich, USA). Ki-67 and ER- $\alpha$ labeling indexes (LI\%) in mammary glands were calculated as the number of positively marked epithelial cells divided by the total number of cells positive and negative scored $\times 100$ (400-500 cells/mammary gland/per animal) [37]. Apoptosis was analyzed in hematoxylin/eosin (HE)-stained slides, using morphological criteria [39]. Apoptosis index was calculated as the number of apoptotic epithelial cells divided by the total number of cells scored (400-500 cells/mammary gland).

\section{Western Blotting}

Mammary tissue samples were homogenized in lysis buffer (Tris- $\mathrm{HCl} 500 \mathrm{nM} \mathrm{pH} \mathrm{7.6;} \mathrm{NaCl} 0.2 \mathrm{M}$; Triton X-100 1\%; $\mathrm{CaCl} 210 \mathrm{nM}$; protease inhibitor cocktail $2 \mu \mathrm{L} / 100 \mathrm{~mL}$ (Sigma-Aldrich, USA)) in the proportion of $30 \mathrm{mg}$ of tissue/ $100 \mu \mathrm{L}$ of buffer and kept at $4{ }^{\circ} \mathrm{C}$ for $2 \mathrm{~h}$. After this procedure, the extracted material ( 1 pup/litter, $n=05$ each group) was centrifuged at $4000 \mathrm{rpm}$ for $20 \mathrm{~min}$ at $4{ }^{\circ} \mathrm{C}$ and the supernatant was collected for protein quantification using the Bradford 
method. Then, the samples were thawed and were applied in gel $10 \mu \mathrm{L}$ of the sample with $10 \mu \mathrm{L}$ of Laemmli loading buffer (2\% SDS, $10 \%$ glycerol, $0.04 \mathrm{mg} / \mathrm{mL}-1$ bromophenol blue, $0.12 \mathrm{~mol} \mathrm{~L}^{-1}$ Tris-HCl pH 6.8 , and $0.28 \mathrm{~mol} \mathrm{~L}^{-1} \beta$ mercaptoethanol). An amount of $70 \mu \mathrm{g}$ of total protein was fractioned by SDS-PAGE gel (10 or 12\%) and stained with Precision Plus Protein All Blue Standards (Bio-Rad Laboratories, USA) to confirm the equal loading of each sample. Proteins were transferred from gel to a nitrocellulose membrane (Bio-Rad Laboratories, USA). Nonspecific binding sites were blocked using $5 \%$ bovine serum albumin solution (BSA) in phosphate-saline buffer (PBS-T, NaH2PO4. $\mathrm{H} 2 \mathrm{O} 0.1 \mathrm{~mol} / \mathrm{L}, \mathrm{Na} 2 \mathrm{HPO} 4 \cdot 7 \mathrm{H} 2 \mathrm{O} 0.1 \mathrm{~mol} / \mathrm{L}, \mathrm{NaCl}$ $0.15 \mathrm{~mol} / \mathrm{L}$, Tween-20 0.1\%, H 7.4) for $1 \mathrm{~h}$. Membranes were incubated with mouse monoclonal anti-Bcl-2 (C-2) (sc-7382, 26KDa, 1:1000 dilution, Santa Cruz Biotechnology, USA) and mouse monoclonal anti-Bcl-xl (H-5) (sc-8392, $30 \mathrm{KDa}$, 1:1000 dilution, Santa Cruz Biotechnology, USA) or goat polyclonal anti- $\beta$-actin (sc1815, C-11, $43 \mathrm{KDa}, 1: 1000$ dilution, Santa Cruz Biotechnology, USA) primary antibodies diluted in 5\% BSA solution for 1-2 h. After four wash steps using PBS-T, the membranes were incubated with specific horseradish conjugated secondary antibodies, according to the primary antibodies (rabbit anti-mouse IgG, sc-3589 or donkey anti-goat IgG, sc 2020, Santa Cruz Biotechnology, USA) for $1-2 \mathrm{~h}$. Finally, after five wash steps, the membranes were submitted to immunoreactive protein signals detected using an Amersham ECL Select Western Blotting Detection Reagent (GE Healthcare Life Sciences UK Limited, UK), according to the manufacturer's instructions. Signals were captured by a G:BOXChemi system (Syngene, UK) controlled by an automatic software (GeneSys, Syngene, UK). Band intensities were quantified using a densitometry analysis software (ImageJ software, Austria). Finally, the protein expression was reported as fold change according to the $\beta$-actin protein expression used as a normalizer.

\section{Tumor Mammary Analysis}

After MNU administrations, all animals were examined three times per week to record the presence of gross mammary tumors, the number and location of each palpable mass in different mammary gland complexes. The body weight was also recorded individually once a week after two MNU administrations. Mammary tumors were collected by an incision from the ventral pubic region to the chest. The number, location, and net weight of each tumor mass that was surgically removed from the different mammary gland complexes were carefully recorded. For a histological analysis, tumor samples were collected and fixed in 10\% phosphate-buffered formalin for $24 \mathrm{~h}$, embedded in paraffin blocks, cut into 5 - $\mu \mathrm{m}$-thick sections, and stained with HE. Mammary lesions were classified according to the previously published criteria [6].

\section{Statistical Analysis}

Changes in body weight and food intake, as well as mammary gland outgrowth, number of TEBs and TDs, and tumor multiplicity were analyzed by ANOVA or Kruskal-Wallis tests and a Tukey's post hoc test. The statistical analysis of incidence of tumor weight and different histological tumor types were examined using a chi-square test or Fischer's exact test. Statistics for body weight and food consumption parameters for female offspring during PNDs 1-21 was performed using the litter as a unit of measure. Statistics for reproductive (serum hormones and vaginal opening analysis) and mammary gland (morphology, Ki-67, and ER- LI\%, molecular analysis) parameters was performed using one female/litter (selected randomly) while tumor parameters (incidence, multiplicity, and histological phenotypes) were performed using one to two female/litter (selected randomly) as the unit of measure. The statistical analysis was performed using Jandel Sigma Stat Software (Jandel Corporation, San Rafael, CA, USA), and graphs were generated using GraphPad Prism software (Version 6.01, La Jolla, CA). Statistical differences were considered significant with $p<0.05$.

\section{Results}

\section{General Observations}

There was no significant difference in maternal body weight gain, food consumption, and reproductive outcomes (i.e., gestation length, litter size and sex ratio, and no postnatal death) during gestation and lactation periods among the groups (data not shown). At birth (PND 0), lactation (PNDs 1-21) and prepubertal and early pubertal periods (PNDs 22 to 51), body weight from female offspring was similar among the groups (Table 1). In this last period, food consumption did not differ among the groups (data not shown).

Serum estrogen and progesterone levels and the vaginal opening (VO) period were evaluated as parameters of female offspring reproductive development. However, serum hormones and the VO data did not differ among the groups, independently of maternal TCDD and/or Res treatments (Table 1).

\section{Mammary Gland Analysis at PND 22}

Mammary gland outgrowth parameters evaluated (i.e., TEB, TD, and lateral and longitudinal growth) are showed in Fig. 2. There was a significant reduction $(p<0.003$ and $p<0.020)$ in the mammary gland transverse and longitudinal growths in female offspring whose dams were exposed to TCDD on GD 15 when compared to TCDD + Res, Res and control groups, and Res and control groups, respectively. Also, there 
Table 1 Reproductive outcomes from female offspring rats after maternal TCDD and/or resveratrol exposure

\begin{tabular}{|c|c|c|c|c|}
\hline \multirow[t]{2}{*}{ Parameters } & \multicolumn{4}{|c|}{ Experimental groups } \\
\hline & TCDD & TCDD + Res & Res & Control \\
\hline \multicolumn{5}{|c|}{ Body weights (g) } \\
\hline PND 0 & $6.73 \pm 0.21$ & $6.87 \pm 0.13$ & $7.46 \pm 0.24$ & $6.99 \pm 0.37$ \\
\hline PND 07 & $14.49 \pm 1.69$ & $15.85 \pm 1.89$ & $16.86 \pm 0.88$ & $16.44 \pm 0.73$ \\
\hline PND 14 & $30.32 \pm 2.60$ & $32.21 \pm 1.74$ & $33.31 \pm 2.33$ & $33.03 \pm 1.65$ \\
\hline PND 22 & $50.91 \pm 2.89$ & $53.52 \pm 2.68$ & $53.32 \pm 1.46$ & $54.41 \pm 1.80$ \\
\hline PND 51 & $163.22 \pm 12.07$ & $170.59 \pm 15.41$ & $178.06 \pm 16.04$ & $175.03 \pm 12.58$ \\
\hline \multicolumn{5}{|c|}{ Estradiol levels $(\mu \mathrm{g} / \mathrm{mL})$} \\
\hline PND 22 & $23.76 \pm 5.54$ & $24.77 \pm 6.11$ & $26.10 \pm 5.49$ & $26.88 \pm 4.16$ \\
\hline PND 51 & $52.20 \pm 13.56$ & $50.40 \pm 11.95$ & $56.43 \pm 10.81$ & $58.24 \pm 10.28$ \\
\hline \multicolumn{5}{|c|}{ Progesterone levels (ng/mL) } \\
\hline PND 22 & $13.59 \pm 4.21$ & $10.26 \pm 3.16$ & $12.11 \pm 5.21$ & $11.76 \pm 3.63$ \\
\hline PND 51 & $20.93 \pm 6.08$ & $26.72 \pm 6.23$ & $25.43 \pm 6.17$ & $25.01 \pm 5.62$ \\
\hline \multicolumn{5}{|c|}{ Vaginal opening (days) } \\
\hline PND $28-40$ & $35.09 \pm 2.25$ & $32.75 \pm 2.3$ & $34.60 \pm 1.58$ & $33.83 \pm 2.48$ \\
\hline
\end{tabular}

Values are mean $\pm \mathrm{SD}$. TCDD 2,3,7,8-tetrachlorodibenzo-p-dioxin $(1 \mu \mathrm{g} / \mathrm{kg})$ administered at gestational day 15

Res resveratrol (20 mg/kg) daily administered during gestation and lactation (see details in the Materials and Methods section); $P N D$ postnatal day

was a significant increase $(p<0.020$ and $p<0.001)$ in number of TEB and TD structures in the mammary gland from the female offspring whose dams were exposed to TCDD on GD 15 when compared to the control group and other groups (TCDD + Res, Res, and control), respectively.

\section{Mammary Gland Analysis After First MNU Administration at PND 24}

As a single MNU dose cause a significant increase in DNA damage and apoptosis in the mammary gland [40], we investigated as maternal resveratrol could differently modify mammary gland susceptibility or resistance to cancer initiation. From the 91 genes in the TLDA analyzed (Supplementary Data 2), Bcl-2 was upregulated and Bax and Caspase-3 were downregulated $(0.03<p<0.04)$ in the mammary gland of female offspring from the TCDD group, while Ahrr was upregulated $(p<0.02)$ in the mammary gland of the TCDD + Res group when compared to the control group, at $48 \mathrm{~h}$ after the first carcinogen administration (Fig. 3).

Ki-67 and ER- $\alpha$ labeling indexes (LI\%), apoptosis index (AI\%), and Western blot analysis for bcl-2 and bcl-xl proteins were evaluated in the mammary gland (Figs. 4 and 5), at $48 \mathrm{~h}$ after the first carcinogen administration. The Ki-67 and ER- $\alpha$ labeling indexes (LI\%) in mammary epithelial cells were similar among the groups whereas the apoptosis index (AI\%) was significant lower $(p<0.01)$ in the mammary gland from the female offspring whose dams were exposed to TCDD on GD 15 when compared to the other groups (TCDD + Res, Res, and control) (Fig. 4).
The Western blot assay revealed a significant increase $(p<0.01$ and $p<0.05)$ in bcl-2 and bcl-x protein levels in the mammary gland from the female offspring whose dams were exposed to TCDD on GD 15 when compared to the other groups (TCDD + Res, Res, and control) (Fig. 5b-c).

\section{Mammary Tumor Development and Histopathological Analyses at PND 180}

The cumulative number of palpable mammary tumors and the incidence of tumors observed throughout the experimental period (23 weeks after first MNU administration) are presented in Fig. 6. At PND 180, the female offspring from the dams exposed to TCDD on GD 15 developed a higher mean number of mammary tumors $(p<0.005)$ than those in the other groups (Table 2). A significant increase $(p=0.026)$ in the incidence of mammary tumor showing median $(2-5 \mathrm{~g})$ net weight was observed in female offspring from the dams exposed to TCDD on GD 15 when compared to other groups (Table 2). The histopathological analyses indicated that most of MNU-induced mammary tumors showed an expansive growth pattern with local invasive areas, showing papillary, tubular, cribiform, and mixed phenotype patterns (Table 2, but without a significant difference among the groups.

\section{Discussion}

The results of the present study indicated that maternal resveratrol reversed the most of the mammary gland changes 
Fig. 2 a Mammary gland whole mounts: $L N$ lymph node, $L a G$ lateral or transverse growth, $L o G$ longitudinal growth or ductal elongation. b Details of one terminal end bud (TEB) and one terminal duct (TD). c-d Data from lateral growth and longitudinal measures $(\mathrm{cm})$ of mammary epithelial tree. e-f Data from mean number of TEB and TD in external margin of mammary epithelial tree. Values expressed as mean $\pm \mathrm{SD}(n=05$ each group, 1 female/

litter).*Different from the TCDD + Res, Res, and control groups; $p=0.003$ (LaG) and $p<0.001$ (TD); **Different from the Res and control groups; $p=0.020$ (LoG); ***Different from the TCDD + Res, Res, and control groups, $p<0.020$ (TEB)
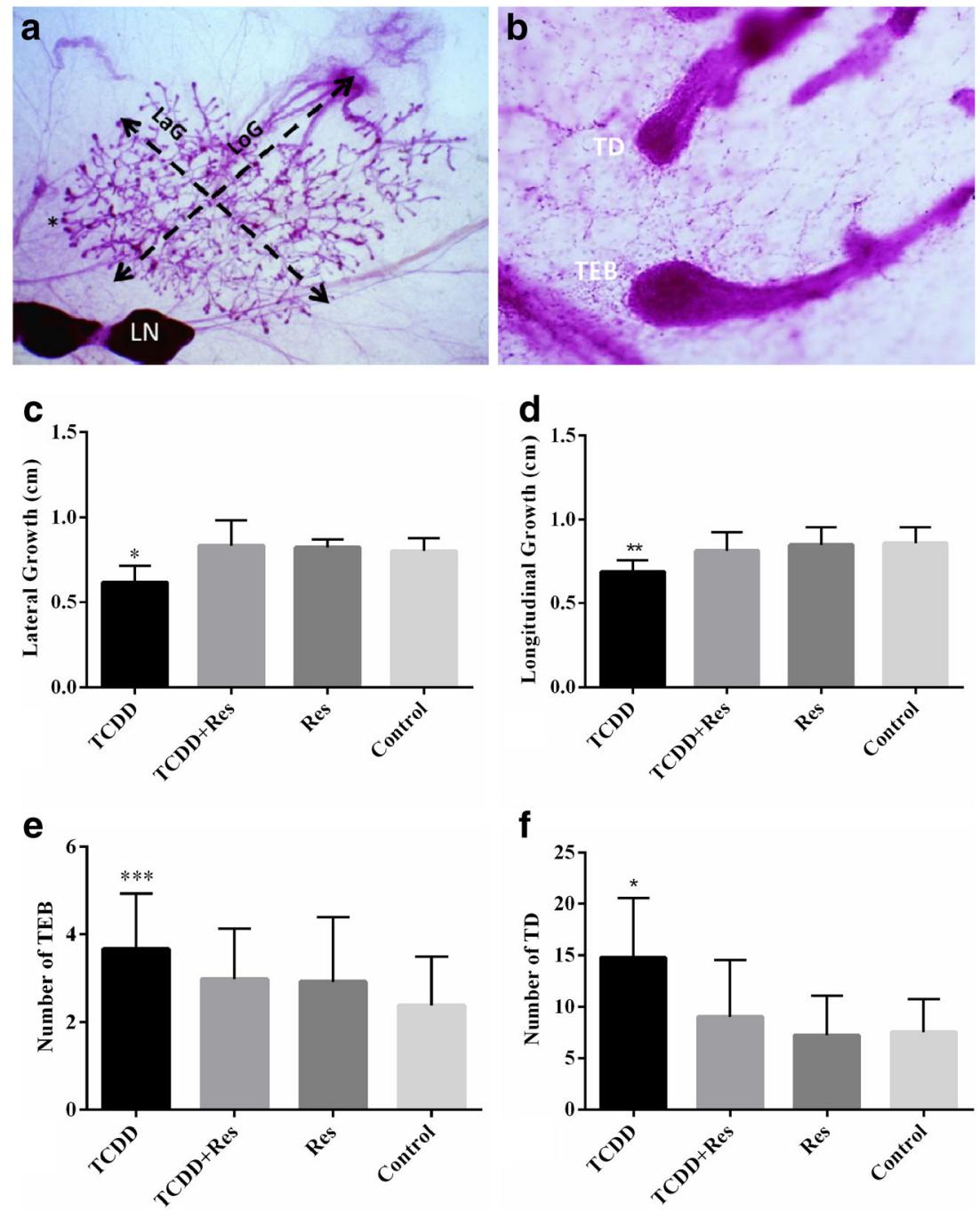

induced by prenatal TCDD exposure in the female offspring and reduced the susceptibility to MNU-induced mammary cancer in adulthood. The lower risk for mammary cancer in female offspring may be due to a favorable apoptotic response observed after a first MNU administration but without involving changes in AhR, ki-67, or estrogen receptor gene expression or Ki-67 or RE- $\alpha$ labeling index, which corroborate with other studies $[15,19]$.

Some studies have showed that the female offspring rats from dams treated with TCDD $(1 \mu \mathrm{g} / \mathrm{kg}$ b.wt.) on GD 15 presented lower body weight values at early parturition and in post-weaning than those from dams only treated with the vehicle $[16,41]$. Also, maternal TCDD exposure could be associated with vaginal opening and estrous cycle changes in female offspring $[16,41,42]$ while other studies did not observe these noxious effects from this dioxin in the female offspring $[43,44]$. Puberty is an event that coincides with the age of vaginal opening and a gradual increase in the secretion of gonadotropic hormones by the pituitary, which leads, in turn, to an increase in serum sexual hormone levels [45]. In the present study, no significant changes were observed in body weight, hormonal serum levels, and in the mean vaginal opening day among female offspring groups, suggesting the absence of a clear adverse effect of TCDD and/or Res on the onset of puberty in female offspring.

Various environmental endocrine disrupters and/or dietary occurring compounds can interfere with mammary gland development mainly on the number of TEB and ductal branches, resulting in lower or higher tumor susceptibility late in life $[8$, 46]. A suitable increase in the number of TEB/TD structures has been considered a major risk factor for increased susceptibility to chemically induced mammary carcinogenesis in rodents $[8,46]$. Some rodent studies indicate that prenatal TCDD exposure impairs mammary gland differentiation, increasing the number of undifferentiated terminal structures in female offspring when analyzed in different prepubertal and pubertal periods [13-16, 19, 42]. In the present study, prenatal TCDD exposure resulted in an increased number of TEB and TD structures and in a lower lateral and longitudinal growth of the mammary gland in relation to the control group on PND 
Fig. 3 Relative quantification (R.Q) of genes differently expressed in the mammary gland from female offspring at PND 24 ( $n=5$ each group, 1 female/litter), $48 \mathrm{~h}$ after the first MNU administration. *Different from the control group $(0.02<p<0.04)$ with fold change $>1.5$ (upregulation) and fold change $<0.5$ (downregulation) in relation to the control group.

Ahrr- Ensembl ID:

ENSRNOG00000014721;

Caspase 3-Ensembl ID:

ENSRNOG00000010475; Bcl-2Ensembl ID:

ENSRNOG00000002791; Bax-

Ensembl ID:

ENSRNOG00000020876
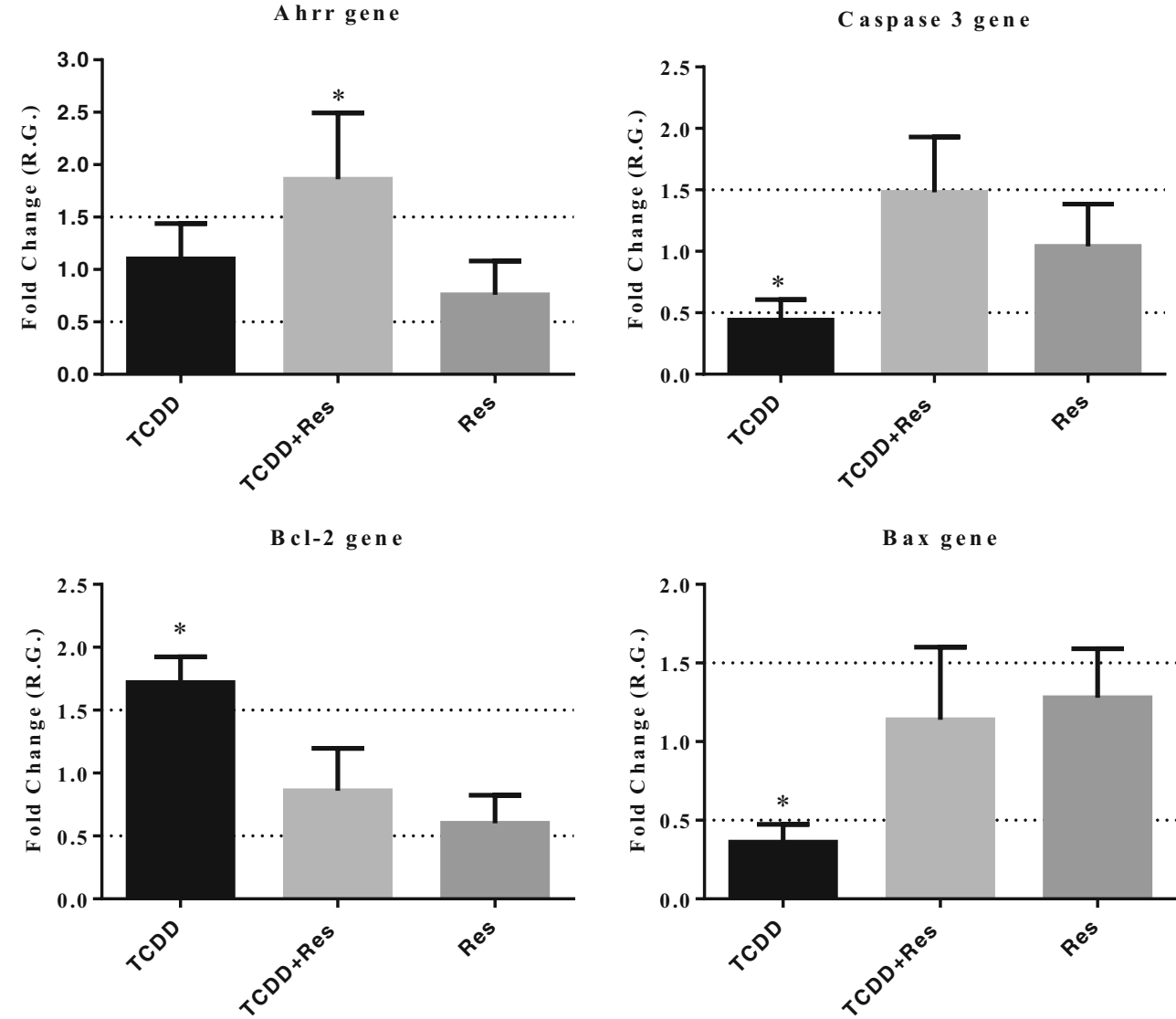

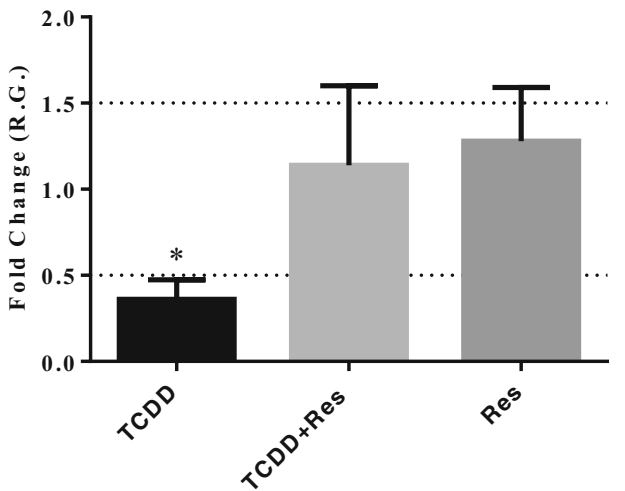

22. On the other hand, Papoutsis et al. (2015) showed that maternal dietary Res (7 ppm), from GD 7 to parturition, reduced the number of TEB plus TD structures and normalized the number of mammary alveolar buds and lobules in female offspring prenatally exposed to TCDD on PND 71 but not on PND 46 [15]. Maternal Res reduced also the number of undifferentiated terminal structures resulting in protective effects against the noxious effects of prenatal TCDD exposure in

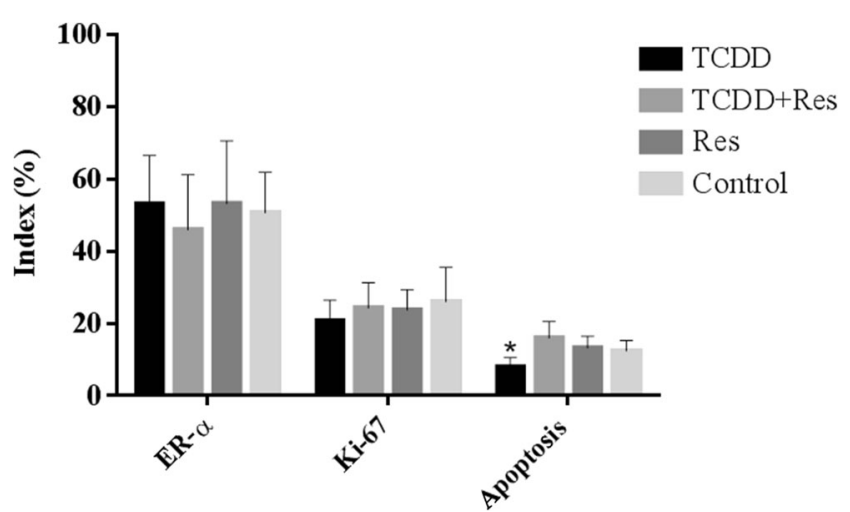

Fig. 4 ER- $\alpha$ and Ki-67 labeling index (LI\%) and apoptotic index (AI\%) in the mammary gland from female offspring at PND $24(n=05$ each group, 1 female/litter), $48 \mathrm{~h}$ after the first MNU administration. *Different from the control group $(p<0.01)$ sexually immature female offspring (PND 22). In addition, our findings indicate that female offspring prenatally treated with TCDD + Res and Res developed fewer tumors than the TCDD and control groups, indicating the possible protective role of this polyphenol on the initiation stage of mammary carcinogenesis.

Molecular analysis showed that some genes and protein related to apoptosis were modified on the mammary gland from female offspring prenatally exposed to TCDD after a first carcinogen insult. Apoptosis is an important regulatory process to protect against cancer development [47]. It provides an innate cellular defense against the onset of cancer and its progression by removing cells with genomic instability and by deleting cells with DNA damage induced by genotoxic agents such as carcinogens $[47,48]$. The regulators of apoptosis are divided into two major programs: the extrinsic program involves extracellular signals of death, and the intrinsic program involves signals of an intracellular origin [47, 48]. Both intrinsic and extrinsic apoptotic programs involve the activation and/or suppression of several gene families. Among these families, bcl-2, bcl-x proteins, and other members protect the cells against apoptosis, whereas bax and related proteins potentiate the cell death $[49,50]$. The bcl-2/bax ratio intrinsically controls the relative susceptibility of target cells to induce apoptosis [49, 50]. 

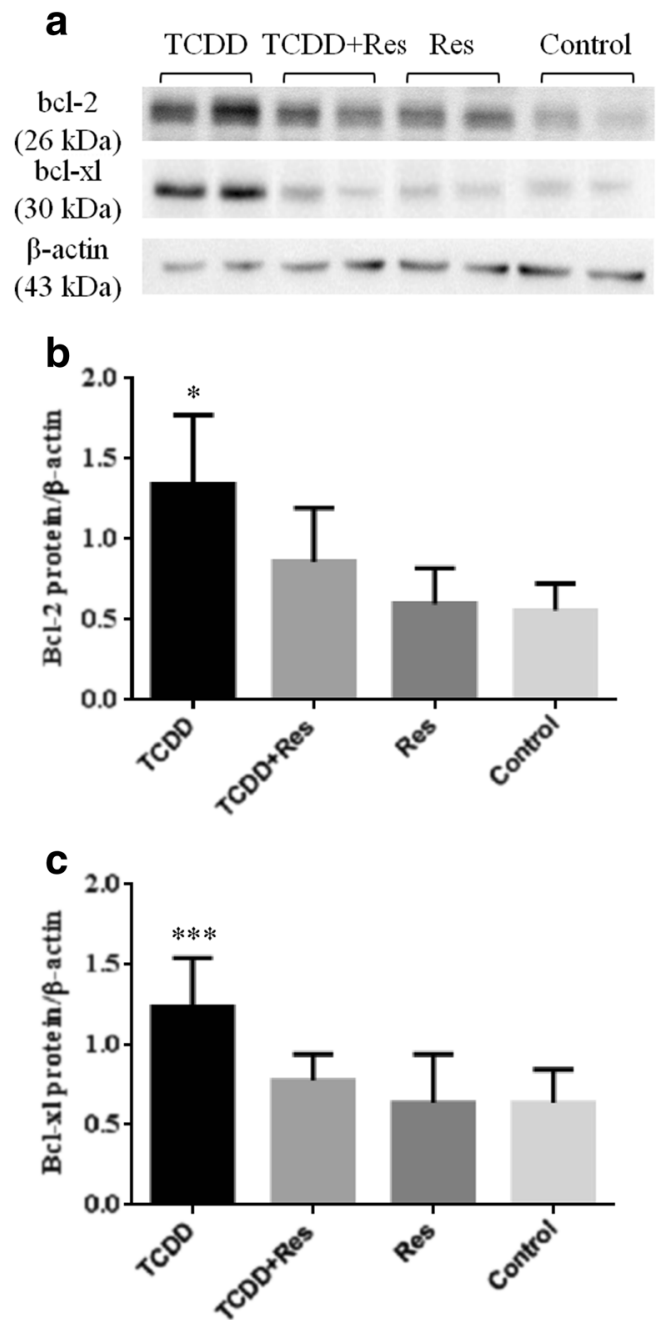

Fig. 5 a Representative immunoblots of bcl-2, bcl-xl, and $\beta$-actin protein assayed by Western blotting. $\mathbf{b}$ and $\mathbf{c}$ Data from IOD calculated from the ratio of bcl-2 and bcl-xl to $\beta$-actin levels in the mammary gland from female offspring at PND 24 ( $n=05$ each group, 1 female/litter), $48 \mathrm{~h}$ after the first MNU administration. Values are means \pm SD. *, $* * *$ Different from the control group $p<0.01$ (bcl-2) and others groups, $p<0.05$ (bcl-xl), respectively

MNU carcinogen is a direct methylating agent that reacts with key cellular macromolecules, including DNA, causing relatively high levels of O6-methylguanine adducts, which results in a predominant DNA lesion and can potentially initiate cancer in susceptible target tissue, including the mammary gland [51]. Thus, MNU has been used as a potent carcinogen in chemically induced rat mammary carcinogenesis models using prepubertal and pubertal female rats [7, 51], exerting acute cytotoxicity on mammary epithelial cells by inducing DNA damage and/or cell death [40]. Our results indicate that prenatal TCDD exposure led to a reduction in apoptosis indexes in mammary epithelial cells after the first MNU administration. This finding suggests that it may be deleterious in the early stages of mammary carcinogenesis, by reducing
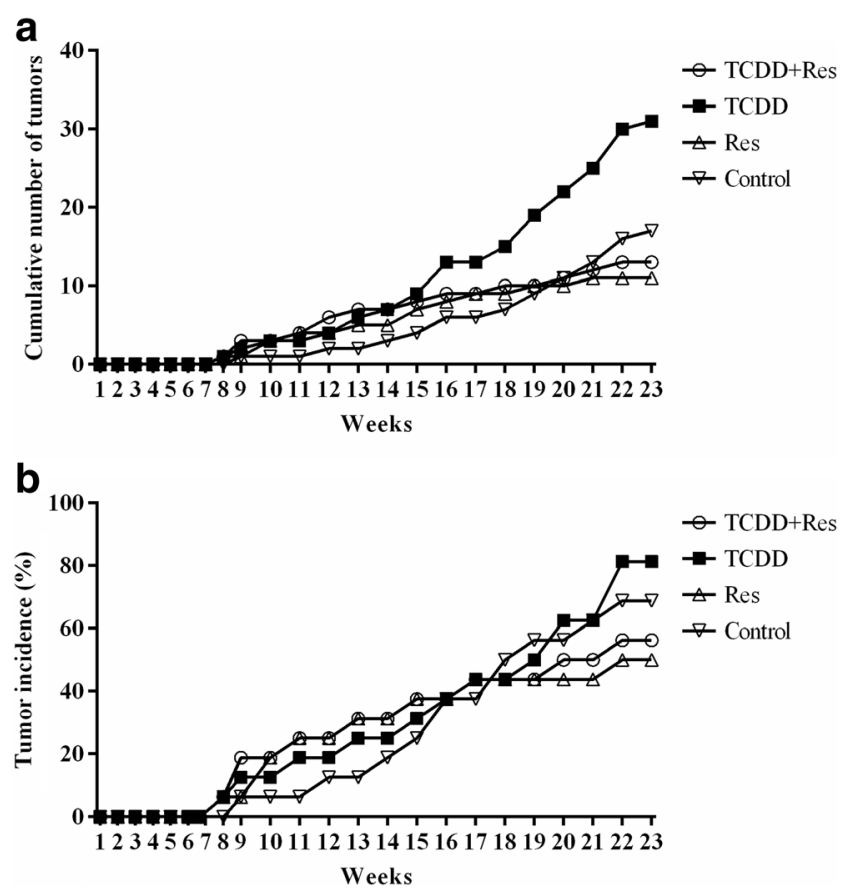

Fig. 6 a The cumulative number of palpable mammary tumors as a function of time after two doses of N-nitroso-N-methylurea (MNU). b Percentage of palpable tumor-free female offspring as a function of time after two doses of MNU

the potential elimination of epithelial cells with MNUinduced DNA damage. As such, maternal Res treatment reduced the deleterious effects of TCDD exposure as detected by a favorable balance of apoptosis-related gene/protein expression and the cell death index in the mammary gland observed after a first MNU insult, resulting in a reduced number of mammary tumors in adulthood. However, the potential of resveratrol to affect apoptotic pathways in the mammary gland needs to be investigated over a wider dosage range and in an approach with or without an associated carcinogen insult.

The AhR and its nuclear partner AhR nuclear translocator (ARNT) are two founding members of the bHLH-PAS family of heterodimeric transcriptional regulators $[52,53]$. AhR is located in the cytoplasm associated with heat shock protein 90 (hsp90), a 38-kDa, immunophilin-related protein (xap2), and other proteins $[52,53]$. A ligand binding to the AhR induces a translocation of the complex (Ahr/hsp90/xap2) into the nucleus, and the AhR-ligand complex dissociates from associated proteins and dimerizes with ARNT. The ligandactivated AhR-ARNT transcriptionally active complex binding on to its specific DNA recognition site, the xenobioticresponsive element (XRE), within the promoter region of AhR-regulated genes results in their increased transcription $[52,53]$. TCDD is a prototypical ligand to AhR since this dioxin interacts with the receptor AhR complex with high affinity $[54,55]$. The AhR/TCDD complex is translocated to the nucleus, and it makes complex with ARNT in order to activate the transcription of several genes such as Phase I 
Table 2 Data of mammary tumor induced by MNU administrations in female offspring from dams treated with TCDD and/or RES at PND 180

\begin{tabular}{|c|c|c|c|c|}
\hline \multirow[t]{2}{*}{ Parameters } & \multicolumn{4}{|c|}{ Group/treatment ${ }^{\mathrm{a}}$} \\
\hline & TCDD + Res & TCDD & Res & Control \\
\hline Effective number of rats & 16 & 16 & 16 & 16 \\
\hline Incidence of tumor-bearing rats & $9 / 16(56 \%)$ & $13 / 16(81 \%)$ & $8 / 16(50 \%)$ & $12 / 16(69 \%)$ \\
\hline Number of tumors & $0.81 \pm 0.23$ & $1.94 \pm 0.40 *$ & $0.69 \pm 0.20$ & $0.94 \pm 0.17$ \\
\hline Total number of tumors & 13 & 31 & 11 & 17 \\
\hline \multicolumn{5}{|l|}{ Tumor weight $(\%)^{\mathrm{b}}$} \\
\hline$<2.0 \mathrm{~g}$ & $7(54 \%)$ & $7(23 \%)$ & $5(45 \%)$ & $9(53 \%)$ \\
\hline $\mathrm{g}$ & $4(31 \%)$ & $15(48 \%)^{* *}$ & $3(27 \%)$ & $2(12 \%)$ \\
\hline$>5.0 \mathrm{~g}$ & $2(15 \%)$ & $9(29 \%)$ & $3(27 \%)$ & $6(35 \%)$ \\
\hline \multicolumn{5}{|l|}{ Histological types } \\
\hline Tubular & $2 / 13(15 \%)$ & $4 / 31(13 \%)$ & $2 / 11(18 \%)$ & $2 / 17(12 \%)$ \\
\hline Papillary & $7 / 13(54 \%)$ & $18 / 31(58 \%)$ & $3 / 11(27 \%)$ & $5 / 17(29 \%)$ \\
\hline Cribiform & $1 / 13(8 \%)$ & $5 / 31(16 \%)$ & $4 / 11(36 \%)$ & $5 / 17(29 \%)$ \\
\hline Tubular/papillary & 0 & $2 / 31(6 \%)$ & 0 & $1 / 17(6 \%)$ \\
\hline Papillar/cribiform & $1 / 13(8 \%)$ & $2 / 31(6 \%)$ & $2 / 11(18 \%)$ & $4 / 17(24 \%)$ \\
\hline Tubular/cribiform & $2 / 13(15 \%)$ & 0 & 0 & 0 \\
\hline
\end{tabular}

*Different from other groups, $p<0.005$

$* *$ Different from control group, $p=0.026$

${ }^{a} T C D D$ 2,3,7,8-tetrachlorodibenzo-p-dioxin $(1 \mu \mathrm{g} / \mathrm{kg})$ administered at gestational day $15 ;$ Res resveratrol $(20 \mathrm{mg} / \mathrm{kg})$ daily administered during gestation and lactation (see details in the Materials and Methods section)

${ }^{\mathrm{b}}$ Tumor weight distribution (\%) among the groups showing light $(<2 \mathrm{~g})$, median $(2-5 \mathrm{~g})$, and heavy $(>5 \mathrm{~g})$ net weight

(CYP1A1, CYP1A2, CYP1B1, and CYP2S1) and Phase II (UDP-glucuronosyltransferase UGT1A6, NAD(P)H-dependent quinone oxydoreductase-1 NQO1, the aldehyde dehydrogenase ALDH3A1 and several glutathione-S-transferases) and other genes participating in other cellular responses $[54,55]$. If aryl-hydrocarbon receptor repressor (AhRR) interacts with the AhR/Arnt-TCDD complex, the transcription is inhibited [54, 55]. Thus, the increase in mRNA AhRR by maternal resveratrol, an AhR antagonist, could represent a protective effect against AhR-TCDD activation, as previously demonstrated [15]. In fact, AhR plays a pivotal role in the development of breast cancer by suppress apoptosis, and indicate that the use of AhR antagonists with chemotherapeutic agents may effectively synergize the elimination though the apoptosis of breast cancer cells $[28,56]$.

In conclusion, the present study indicated that maternal resveratrol leads to ameliorate mammary gland changes induced by prenatal TCDD. In addition,, the findings provided the first evidence that maternal resveratrol reduces the susceptibility to MNU-induced mammary tumors development in female offspring prenatally exposed to TCDD, possibly from a favorable balance of apoptosis at the early stages of tumor initiation. However, further assessment is needed on the potential role of this polyphenol and its molecular mechanisms involved in protecting against mammary tumorigenesis.
Acknowledgements Tassia C. de Lima e Silva and Odair H.G. Diniz were recipients of a fellowship from the DINTER program (UFPE$\mathrm{UNESP} / \mathrm{CAPES}$ ) and PIBIC/CNPq/UNESP, respectively.

Compliance with Ethical Standards Animal protocols used in this study were consistent with the Ethical Principles for Animal Research adopted by the Brazilian College of Animal Experimentation (COBEA) and approved by the School of Medicine/UNESP Ethical Committee for Animal Research (CEUA, protocol number 1049/13).

Financial Support Luis F. Barbisan was a recipient of support research from DINTER/CAPES and FAPESP (2012/13004-1, supplies for molecular analysis).

Conflict of Interest The authors declare that they have no conflict of interest.

\section{References}

1. Ferlay J, Soerjomataram I, Dikshit R, Eser S, Mathers C, Rebelo M, Parkin DM, Forman D, Bray F (2015) Cancer incidence and mortality worldwide: sources, methods and major patterns in GLOBOCAN 2012. Int J Cancer 136(5):E359E386. doi:10.1002/ijc. 29210

2. Torre LA, Siegel RL, Ward EM, Jemal A (2016) Global cancer incidence and mortality rates and trends - an update. Cancer Epidemiol Biomark Prev 25(1):16-27. doi:10.1158/1055-9965. EPI-15-0578 
3. Di Renzo GC, Conry JA, Blake J, DeFrancesco MS, DeNicola N, Martin JN Jr, McCue KA, Richmond D, Shah A, Sutton P, Woodruff TJ, van der Poel SZ, Giudice LC (2015) International federation of gynecology and obstetrics opinion on reproductive health impacts of exposure to toxic environmental chemicals. Int $\mathbf{J}$ Gynaecol Obstet 131(3):219-225. doi:10.1016/j.ijgo.2015.09.002

4. Diamanti-Kandarakis E, Bourguignon JP, Giudice LC, Hauser R, Prins GS, Soto AM, Zoeller RT, Gore AC (2009) Endocrinedisrupting chemicals: an endocrine society scientific statement. Endocr Rev 30(4):293-342. doi:10.1210/er.2009-0002

5. Medina D (2007) Chemical carcinogenesis of rat and mouse mammary glands. Breast Dis 28:63-68

6. Russo J (2015) Significance of rat mammary tumors for human risk assessment. Toxicol Patho 143(2):145-170. doi:10.1177/ 0192623314532036

7. Macon MB, Fenton SE (2013) Endocrine disruptors and the breast: early life effects and later life disease. J Mammary Gland Biol Neoplasia 18(1):43-61. doi:10.1007/s10911-013-9275-7

8. Hays SM, Aylward LL (2003) Dioxin risks in perspective: past, present, and future. Regul Toxicol Pharmacol 37(2):202-217

9. van den Berg M, Denison MS, Birnbaum LS, Devito MJ, Fiedler H, Falandysz J, Rose M, Schrenk D, Safe S, Tohyama C, Tritscher A, Tysklind M, Peterson RE (2013) Polybrominated dibenzo-p-dioxins, dibenzofurans, and biphenyls: inclusion in the toxicity equivalency factor concept for dioxin-like compounds. Toxicol Sci 133(2):197-208. doi:10.1093/toxsci/kft070

10. Steenland K, Bertazzi P, Baccarelli A, Kogevinas M (2004) Dioxin revisited: developments since the 1997 IARC classification of dioxin as a human carcinogen. Environ Health Perspect 112(13): $1265-1268$

11. Sorg O (2014) AhR signalling and dioxin toxicity. Toxicol Lett 230(2):225-233. doi:10.1016/j.toxlet.2013.10.039

12. Wiberg K, Aberg A, McKone TE, Tysklind M, Hanberg A, MacLeod M (2007) Model selection and evaluation for risk assessment of dioxin-contaminated sites. Ambio 36(6):458-466

13. Vorderstrasse BA, Fenton SE, Bohn AA, Cundiff JA, Lawrence BP (2004) A novel effect of dioxin: exposure during pregnancy severely impairs mammary gland differentiation. Toxicol Sci 78(2):248-257

14. Lew BJ, Collins LL, O'Reilly MA, Lawrence BP (2009) Activation of the aryl hydrocarbon receptor during different critical windows in pregnancy alters mammary epithelial cell proliferation and differentiation. Toxicol Sci 111(1):151-162. doi:10.1093/toxsci/kfp125

15. Papoutsis AJ, Selmin OI, Borg JL, Romagnolo DF (2015) Gestational exposure to the AhR agonist 2,3,7,8-tetrachlorodibenzo-p-dioxin induces BRCA-1 promoter hypermethylation and reduces BRCA-1 expression in mammary tissue of rat offspring: preventive effects of resveratrol. Mol Carcinog 54(4):261-269. doi:10.1002/mc.22095

16. Brown NM, Manzolillo PA, Zhang JX, Wang J, Lamartiniere CA (1998) Prenatal TCDD and predisposition to mammary cancer in the rat. Carcinogenesis 19(9):1623-1629

17. Lewis BC, Hudgins S, Lewis A, Schorr K, Sommer R, Peterson RE, Flaws JA, Furth PA (2001) In utero and lactational treatment with 2,3,7,8-tetrachlorodibenzo-p-dioxin impairs mammary gland differentiation but does not block the response to exogenous estrogen in the postpubertal female rat. Toxicol Sci 62(1):46-53

18. Collins LL, Lew BJ, Lawrence BP (2009) TCDD exposure disrupts mammary epithelial cell differentiation and function. Reprod Toxicol 28(1):11-17. doi:10.1016/j.reprotox.2009.02.013

19. Jenkins S, Rowell C, Wang J, Lamartiniere CA (2007) Prenatal TCDD exposure predisposes for mammary cancer in rats. Reprod Toxicol 23(3):391-396

20. Warner M, Eskenazi B, Mocarelli P, Gerthoux PM, Samuels S, Needham L, Patterson D, Brambilla P (2002) Serum dioxin concentrations and breast cancer risk in the Seveso Women's Health Study. Environ Health Perspect 110(7):625-628
21. Danjou AM, Fervers B, Boutron-Ruault MC, Philip T, ClavelChapelon F, Dossus L (2015) Estimated dietary dioxin exposure and breast cancer risk among women from the French E3N prospective cohort. Breast Cancer Res 17:39. doi:10.1186/s13058015-0536-9

22. Leng L, Li J, Luo XM, Kim JY, Li YM, Guo XM, Chen X, Yang QY, Li G, Tang NJ (2016) Polychlorinated biphenyls and breast cancer: a congener-specific meta-analysis. Environ Int 88:133141. doi:10.1016/j.envint.2015.12.022

23. Carter LG, D’Orazio JA, Pearson KJ (2014) Resveratrol and cancer: focus on in vivo evidence. Endocr Relat Cancer 21(3):R209R225. doi:10.1530/ERC-13-0171

24. Cottart CH, Nivet-Antoine V, Beaudeux JL (2014) Review of recent data on the metabolism, biological effects, and toxicity of resveratrol in humans. Mol Nutr Food Res 58(1):7-21. doi:10.1002/ mnfr.201200589

25. Gambini J, Inglés M, Olaso G, Lopez-Grueso R, Bonet-Costa V, Gimeno-Mallench L, Mas-Bargues C, Abdelaziz KM, GomezCabrera MC, Vina J, Borras C (2015) Properties of resveratrol: in vitro and in vivo studies about metabolism, bioavailability, and biological effects in animal models and humans. Oxid Med Cell Longev 2015:837042. doi: 10.1155/2015/837042

26. Bonnefont-Rousselot D (2016) Resveratrol and cardiovascular diseases. Nutrients 8(5):E250. doi:10.3390/nu8050250

27. Williams LD, Burdock GA, Edwards JA, Beck M, Bausch J (2009) Safety studies conducted on high-purity trans-resveratrol in experimental animals. Food Chem Toxicol 47(9):2170-2182. doi:10. 1016/j.fct.2009.06.002

28. Sinha D, Sarkar N, Biswas J, Bishayee A (2016) Resveratrol for breast cancer prevention and therapy: preclinical evidence and molecular mechanisms. Semin Cancer Biol 40-41:209-232. doi:10. 1016/j.semcancer.2015.11.001

29. Banerjee S, Bueso-Ramos C, Aggarwal BB (2002) Suppression of 7,12-dimethylbenz(a)anthracene-induced mammary carcinogenesis in rats by resveratrol: role of nuclear factor-kappaB, cyclooxygenase 2, and matrix metalloprotease 9. Cancer Res 62(17):4945-4954

30. Whitsett T, Carpenter M, Lamartiniere CA (2006) Resveratrol, but not EGCG, in the diet suppresses DMBA-induced mammary cancer in rats. J Carcinog 5:15

31. Chatterjee M, Das S, Janarthan M, Ramachandran HK, Chatterjee $M$ (2011) Role of 5-lipoxygenase in resveratrol mediated suppression of 7,12-dimethylbenz $(\alpha)$ anthracene-induced mammary carcinogenesis in rats. Eur J Pharmacol 668(1-2):99-106. doi:10.1016/j. ejphar.2011.06.039

32. Bhat KP, Lantvit D, Christov K, Mehta RG, Moon RC, Pezzuto JM (2001) Estrogenic and antiestrogenic properties of resveratrol in mammary tumor models. Cancer Res 61(20):7456-7463

33. Sato M, Pei RJ, Yuri T, Danbara N, Nakane Y, Tsubura A (2003) Prepubertal resveratrol exposure accelerates N-methyl-Nnitrosourea-induced mammary carcinoma in female SpragueDawley rats. Cancer Lett 202:137-145. doi:10.1016/j.canlet.2003. 08.016

34. Nakamura T, Nakai K, Matsumura T, Suzuki S, Saito Y, Satoh H (2008) Determination of dioxins and polychlorinated biphenyls in breast milk, maternal blood and cord blood from residents of Tohoku, Japan. Sci Total Environ 394(1):39-51. doi:10.1016/j. scitotenv.2008.01.012

35. Juan ME, González-Pons E, Munuera T, Ballester J, Rodríguez-Gil JE, Planas JM (2005) Trans-resveratrol, a natural antioxidant from grapes, increases sperm output in healthy rats. J Nutr 135(4):757-760

36. Bojková B, Ahlers I, Kubatka P, Mociková K, Mníchová M, Ahlersová E (2000) Repeated administration of carcinogen in critical developmental periods increases susceptibility of female Wistar:han rats to mammary carcinogenesis induction. Neoplasma 47(4):230-233 
37. Grassi TF, Rodrigues MA, de Camargo JL, Barbisan LF (2011) Evaluation of carcinogenic potential of diuron in a rat mammary twostage carcinogenesis model. Toxicol Pathol 39(3):486-495. doi:10. 1177/0192623310396904

38. de Assis S, Warri A, Cruz MI, Hilakivi-Clarke L (2010) Changes in mammary gland morphology and breast cancer risk in rats. $\mathrm{J}$ Vis Exp 16(44). doi: 10.3791/2260

39. Elmore SA, Dixon D, Hailey JR, Harada T, Herbert RA, Maronpot RR, Nolte T, Rehg JE, Rittinghausen S, Rosol TJ, Satoh H, Vidal JD, Willard-Mack CL, Creasy DM (2016) Recommendations from the INHAND Apoptosis/Necrosis Working Group. Toxicol Pathol 44(2):173-188. doi:10.1177/0192623315625859

40. Bidinotto LT, Costa CA, Costa M, Rodrigues MA, Barbisan LF (2012) Modifying effects of lemongrass essential oil on specific tissue response to the carcinogen $\mathrm{N}$-methyl-N-nitrosurea in female BALB/c mice. J Med Food 15(2):161-168. doi:10.1089/ jmf.2010.0278

41. Kakeyama M, Sone H, Tohyama C (2008) Perinatal exposure of female rats to 2,3,7,8-tetrachlorodibenzo-p-dioxin induces central precocious puberty in the offspring. J Endocrinol 197(2):351-358. doi:10.1677/JOE-08-0062

42. Fenton SE, Hamm JT, Birnbaum LS, Youngblood GL (2002) Persistent abnormalities in the rat mammary gland following gestational and lactational exposure to 2,3,7,8-tetrachlorodibenzo-pdioxin (TCDD). Toxicol Sci 67(1):63-74

43. Flaws JA, Sommer RJ, Silbergeld EK, Peterson RE, Hirshfield AN (1997) In utero and lactational exposure to 2,3,7,8-tetrachlorodibenzop-dioxin (TCDD) induces genital dysmorphogenesis in the female rat. Toxicol Appl Pharmacol 147(2):351-362

44. Gray LE Jr, Ostby JS (1995) In utero 2,3,7,8-tetrachlorodibenzo-pdioxin (TCDD) alters reproductive morphology and function in female rat offspring. Toxicol Appl Pharmacol 133(2):285-294

45. Green MR, McCormick CM (2016) Sex and stress steroids in adolescence: gonadal regulation of the hypothalamic-pituitary-adrenal axis in the rat. Gen Comp Endocrinol 234:110-116. doi:10.1016/j. ygcen.2016.02.004
46. Russo IH, Russo J (1996) Mammary gland neoplasia in long-term rodent studies. Environ Health Perspect 104(9):938-967

47. Hanahan D, Weinberg RA (2011) Hallmarks of cancer: the next generation. Cell 144(5):646-674. doi:10.1016/j.cell.2011.02.013

48. Roos WP, Thomas AD, Kaina B (2016) DNA damage and the balance between survival and death in cancer biology. Nat Rev Cancer 16(1):20-33. doi:10.1038/nrc.2015.2

49. Kuwana T, Newmeyer DD (2003) Bcl-2-family proteins and the role of mitochondria in apoptosis. Curr Opin Cell Biol 15(6):691-699

50. Brunelle JK, Letai A (2009) Control of mitochondrial apoptosis by the Bcl-2 family. J Cell Sci 122(Pt 4):437-441. doi:10. $1242 /$ jcs. 031682

51. Faustino-Rocha AI, Ferreira R, Oliveira PA, Gama A, Ginja M (2015) N-methyl-N-nitrosourea as a mammary carcinogenic agent. Tumour Biol 36(12):9095-9117. doi:10.1007/s13277-015-3973-2

52. Pocar P, Fischer B, Klonisch T, Hombach-Klonisch S (2005) Molecular interactions of the aryl hydrocarbon receptor and its biological and toxicological relevance for reproduction. Reproduction 129(4):379-389

53. Puga A, Ma C, Marlowe JL (2009) The aryl hydrocarbon receptor cross-talks with multiple signal transduction pathways. Biochem Pharmacol 77(4):713-722. doi:10.1016/j.bcp.2008.08.031

54. Haarmann-Stemmann T, Abel J (2006) The aryl hydrocarbon receptor repressor (AhRR): structure, expression, and function. Biol Chem 387(9):1195-1199

55. Vogel CF, Chang WL, Kado S, McCulloh K, Vogel H, Wu D, Haarmann-Stemmann T, Yang G, Leung PS, Matsumura F, Gershwin ME (2016) Transgenic overexpression of aryl hydrocarbon receptor repressor (AhRR) and AhR-mediated induction of CYP1A1, cytokines, and acute toxicity. Environ Health Perspect 124(7):1071-1083. doi:10.1289/ehp.1510194

56. Bekki K, Vogel H, Li W, Ito T, Sweeney C, Haarmann-Stemmann T, Matsumura F, Vogel CF (2015) The aryl hydrocarbon receptor (AhR) mediates resistance to apoptosis induced in breast cancer cells. Pestic Biochem Physiol 120:5-13. doi:10.1016/j.pestbp. 2014.12.021 